\title{
Governança judicial: proposta de modelo teórico-metodológico'
}

\author{
Luiz Akutsu \\ Tribunal de Contas da União (TCU) \\ Brasília / DF - Brasil \\ Tomás de Aquino Guimarães \\ Universidade de Brasília (UnB) / Programa de Pós-Graduação em Administração \\ Brasilia / DF - Brasil
}

\begin{abstract}
Governança judicial é um conceito multifacetado, pouco explorado na literatura, e são raros os estudos desse tema com dados empíricos que analisem as variáveis que o influenciam. Este artigo tem como objetivo propor um modelo teórico-metodológico de governança judicial, cuja aplicação futura permita a coleta de dados para descrever e avaliar a validade da relação entre os construtos e variáveis que o compõem em cada contexto. Premissas da teoria da agência e da teoria de custos de transação, dirigidas originalmente para empresas, foram transpostas para elaboração do modelo. Os procedimentos de coleta de dados incluíram análise documental e realização de 10 entrevistas. $\mathrm{O}$ modelo proposto inclui a sistematização de sete construtos teóricos - accountability; acessibilidade; independência; recursos e estrutura; práticas de governança; ambiente institucional; desempenho - e variáveis componentes desses construtos.
\end{abstract}

Palavras-chave: desempenho judicial; governança judicial; Poder Judiciário; tribunal.

Gobernanza judicial: propuesta de modelo teórico-metodológico

Gobernanza judicial es un concepto multifacético y son escasos los estudios sobre este tema con los datos empíricos que analizan las variables que influyen en ella. Este artículo tiene como objetivo proponer un modelo teórico-metodológico de gobernanza judicial cuya futura aplicación permita describir y evaluar la validez de la relación entre los constructos que lo conforman en cada contexto. Supuestos de la teoría de la agencia y de la teoría de los costes de transacción, inicialmente dirigidas a las empresas, fueran transpuestos para el modelo. Los procedimientos de la recolección de datos incluyen el análisis de documentos y la realización de 10 entrevistas. El modelo propuesto incluye la sistematización de siete

DOI: http://dx.doi.org/10.1590/0034-7612116774

Artigo recebido em 5 maio 2013 e aceito em 27 jan. 2015.

(cc) BY-NC

${ }^{1}$ Pesquisa realizada com apoio financeiro do Conselho Nacional de Desenvolvimento Científico e Tecnológico (CNPq). Em sua versão preliminar, o presente artigo foi apresentado no XXXVII Enanpad, 2013 — Encontro da Associação Nacional de Pós-Graduação e Pesquisa em Administração (EnANPAD), no Rio de Janeiro (RJ), tendo sido incluído entre os três trabalhos da Divisão de Administração Pública indicados para o Prêmio Anpad daquela edição do evento. Este artigo incorpora modificações decorrentes de sugestões de revisores anônimos, a quem os autores agradecem. 
constructos teóricos — accountability; accesibilidad; independencia; recursos y estructura, prácticas de gobernanza; ambiente institucional; desempeño - y las variables componentes de estos constructos.

Palabras clave: desempeño judicial; gobernanza judicial; Poder Judicial; tribunal.

Judicial governance: a theoretical-methodological model proposal

Judicial governance is a multifaceted concept, underexplored in the literature with few empirical studies on this issue that analyze variables that influence it. This article aims to suggest a theoretical-methodological model of judicial governance, whose future application allows data collection to describe and evaluate the validity of the relationship between its constructs and variables in each context. Assumptions of the agency theory and the transaction cost theory, originally addressed to private companies, were incorporated into creation of the model. Procedures for data collection included document analysis and 10 interviews. The suggested model includes the systematization of seven theoretical constructs accountability, accessibility, independence, resources and structure; governance practices; institutional environment; performance - and variable components of these constructs.

Keywords: judicial performance; judicial governance; Judiciary; court.

\section{Introdução}

A baixa acessibilidade da população de menor renda à Justiça, a morosidade e a baixa eficácia das decisões judiciais são algumas das dificuldades crônicas enfrentadas pelos cidadãos que buscam o Poder Judiciário brasileiro (Sadek, 2004). A literatura aponta, contudo, a carência de pesquisas relacionadas à administração da Justiça em geral e, mais especificamente, de estudos teórico-empíricos que abordem aspectos relacionados à disciplina governança judicial e a relacionem com a teoria da agência e com a teoria de custos de transação (Akutsu e Guimarães, 2012). Tais dificuldades crônicas, decorrentes de crescente carga de trabalho, também são observadas em tribunais de países europeus, conforme destaca $\mathrm{Ng}$ (2011); esse autor destaca que abordagens do ponto de vista estritamente jurídico são insuficientes para estudar questões relacionadas à eficiência da atuação de cortes judiciais, enfatizando, em contraponto, a necessidade de criação da disciplina de governança judicial que contemple uma abordagem interdisciplinar que leve em conta as disciplinas do direito, da ciência política, da economia e da administração, para estudar questões relacionadas à eficiência, accountability pública e modernização dos tribunais.

Considerando, por um lado, a relevância do tema governança judicial e, por outro, a escassez de estudos teórico-empíricos que tenham como objeto órgãos do Poder Judiciário (Akutsu e Guimarães, 2012; Ng, 2011), o presente artigo descreve resultados de pesquisa com o objetivo geral de propor um modelo teórico-metodológico de governança judicial, cuja aplicação futura permita a coleta de dados para descrever e avaliar a validade das relações entre os construtos e variáveis que o compõem em cada contexto dos diversos tribunais que integram o Poder Judiciário. Para tanto, o presente estudo tem como objetivos específicos: (a) identificar construtos teóricos que compõem a governança de tribunais; (b) identificar variá- 
veis relacionadas a esses construtos; c) indicar relações teóricas entre variáveis que compõem os construtos do modelo. Suprindo lacunas identificadas em revisão de literatura, o modelo proposto possibilitará a pesquisadores a elaboração futura de instrumentos de coleta de dados para testar hipóteses de relações de interdependência entre construtos teóricos e variáveis do modelo em diversos contextos empíricos.

Este artigo parte do pressuposto de que questões relacionadas à teoria da agência e à teoria de custos de transação são centrais para o estudo da governança de organizações em geral (Andrade e Rosseti, 2009; Williamson, 1996). Dada a complexidade e as inúmeras abordagens sobre o tema governança, contudo, não faz parte do escopo deste estudo comparar e avaliar os diversos conceitos associados ao referido conceito, limitando-se a buscar aprofundar premissas da teoria de custos de transação sintetizadas no modelo esquemático de governança proposto por Williamson (1996) para avaliar a eficiência das transações realizadas pelas organizações. As propostas de Williamson (1996) foram complementadas, no modelo proposto, por premissas da teoria da agência (Jensen e Meckling, 1976; Eisenhardt, 1989) para questões relacionadas ao conflito entre agentes e principais dos tribunais que integram o Poder Judiciário.

Assim, para desenvolver o modelo proposto, foram adotadas as principais premissas da teoria da agência (TA) e da teoria de custos de transação (TCT), as quais foram sintetizadas em modelo esquemático de governança proposto por Williamson (1996). Este artigo partiu de tais premissas, formuladas em contextos diversos e dirigidas inicialmente para empresas, transpondo-as para órgãos do Judiciário. A adoção de teorias originalmente dirigidas para empresas ancorou-se no pressuposto de que, embora sejam regidos por arcabouços legais distintos, tanto empresas do setor privado quanto tribunais que integram o Poder Judiciário buscam otimizar a eficiência das transações nas respectivas organizações para alcançar os respectivos objetivos, mas devem, contudo, gerir conflitos de agência para alcançar tais objetivos.

\section{Modelo teórico de governança judicial}

A teoria da agência (Jensen e Meckling, 1976) analisa a relação entre aquele que delega (o principal) e aquele incumbido de executar o trabalho (o agente) a partir da metáfora de contrato entre as partes. Para Eisenhardt (1989), há uma relação de agência quando uma parte (o principal) delega trabalho à outra parte (o agente), que realiza esse trabalho. Para essa autora, a teoria da agência tem como objetivo resolver dois problemas que ocorrem nessa relação.

O primeiro problema ocorre quando "os desejos ou objetivos do principal estão em conflito com os do agente" e "é difícil ou caro para o principal verificar o que o agente está fazendo de fato"; o segundo problema é o de divisão de riscos que ocorre quando "o principal e o agente têm atitudes diferentes em relação ao risco". Nessas situações, o agente e o principal podem preferir agir de formas diversas em razão das preferências de cada um em relação ao 
risco do trabalho que foi acordado entre as partes (Eisenhardt, 1989:58). Tendo em vista que o escopo da presente pesquisa é a governança judicial, relacionada ao setor público, a teoria da agência será utilizada com foco no primeiro problema, uma vez que a análise da propensão ao risco do agente e do principal é mais relevante para empresas, que buscam maximizar o lucro a partir de estratégias e atitudes diversas em relação aos riscos de cada operação.

Além dos conflitos de agência, outro aspecto deve ser considerado ao se examinar práticas de governança: os custos de transação. Para Williamson (1981, 1991), a avaliação dos custos de transação pode ser utilizada para a escolha de estruturas de governança mais eficientes entre alternativas de hierarquia e mercado: empresas que elaboram determinado componente internamente (hierarquia) ou que compram esse componente de um fornecedor autônomo (mercado). O exame dessas alternativas não é relevante para o estudo de governança judicial, uma vez que os órgãos do Poder Judiciário são burocracias legalmente estruturadas, com pouca flexibilidade para demitir servidores concursados e contratar tais serviços no mercado. Não obstante, seus pressupostos são úteis para o exame da eficiência de práticas de governança em situações específicas.

A teoria de custos de transação propõe-se a estudar as organizações com base nos seguintes pressupostos: o reconhecimento de que agentes humanos estão sujeitos à racionalidade limitada e pelo menos alguns agentes são propensos ao oportunismo (Williamson, 1981). Eisenhardt (1989:64) destaca que, além de essas premissas serem as mesmas da teoria da agência, as duas teorias têm variáveis dependentes similares: para a autora, "hierarquias correspondem, grosso modo, a contratos baseados em comportamentos, e mercados correspondem a contratos baseados em resultados".

Embora tenham premissas similares, a teoria da agência e a teoria de custos de transação diferem no foco de análise: a primeira busca examinar o contrato entre partes que cooperam, enquanto a segunda tem como foco as fronteiras da organização (Eisenhardt, 1989). A unidade de análise da teoria da agência é o contrato, mesmo que não escrito, entre o principal e o agente, considerando: a) o interesse pessoal, a racionalidade limitada e o grau de aversão ao risco das partes envolvidas; (b) a assimetria de informações entre o principal e o agente; (c) a possibilidade de ocorrência de comportamento oportunista do agente em decorrência de conflito de seus objetivos com os do principal. Eisenhardt (1989) destaca que, uma vez que a unidade de análise, na teoria da agência, é o contrato que governa a relação entre agente e principal, o foco dessa teoria é justamente determinar o contrato mais eficiente que governa essa relação, de forma a minimizar os problemas que podem ocorrer na relação de agência.

No tocante à teoria de custos de transação, a unidade básica de análise, como o próprio nome sugere, é a transação, assim definida: "uma transação ocorre quando um bem ou serviço é transferido por meio de uma interface separável tecnologicamente" (Williamson, 1981:552). As transações que interessam a essa abordagem são as recorrentes e são examinadas a partir das seguintes dimensões: (a) incerteza; (b) frequência de recorrência da transação; e (c) grau de investimento em ativos específicos necessário para realizar a transação (Williamson, 1981). 
Considerando esse contexto, a teoria de custos de transação foi utilizada, na presente pesquisa, como referencial para avaliar a eficiência de práticas de governança judicial a partir das seguintes premissas: (a) práticas de governança influenciam os custos de transação e, em consequência, a eficiência dos serviços do Poder Judiciário; (b) não existe, a priori, uma estrutura de governança superior às demais - a eficiência das transações depende, entre outros fatores, da adequação de práticas de governança ao respectivo ambiente institucional, para cada situação específica; e (c) os custos de transação podem ser minimizados mediante o alinhamento das transações com práticas de governança que coordenem as ações entre agentes e principais (Williamson, 1981, 1991, 1996).

Quanto à teoria da agência, algumas peculiaridades do setor público merecem ser destacadas, para adequar as premissas dessa abordagem ao conceito de governança judicial. Conforme destaca $\mathrm{Ng}$ (2011), a disciplina governança judicial tem objeto e características próprios e visa à solução de conflitos sociais, individuais e coletivos, buscando identificar práticas que permitam às organizações do Poder Judiciário alocar, de forma mais eficiente, recursos escassos. A governança judicial é ancorada por regras e princípios constitucionais, por leis, normas gerais e instituições, e por recursos, capacidades, práticas e métodos de gestão utilizados para o planejamento, acompanhamento e controle das atividades de organizações encarregadas da prestação de serviços judiciais. Em consonância com a proposta de Ng (2011), argumenta-se neste artigo que a qualidade da governança judicial pode ser medida pela efetividade das decisões judiciais, pela acessibilidade à Justiça e pela equidade, transparência e celeridade com que os serviços judiciais são prestados.

As seguintes características peculiares do setor público que afetam as práticas e as estruturas de governança foram destacadas por Dixit (2002) e por Peres (2007): (a) multiplicidade de principais; (b) multiplicidade de tarefas; (c) reduzida competição; e (d) complexidade de práticas de incentivos para motivar os agentes. Para Dixit (2002), o setor público é caracterizado por órgãos que operam com múltiplos principais que podem agir de forma independente. O conceito de principal adotado por Dixit (2002) para o setor público equipara o principal aos contribuintes, proposto por Andrade e Rossetti (2009), ao efetuarem a transposição do conceito de governança corporativa para governança do Estado.

Embora Dixit (2002) não defina de forma expressa seu conceito de principal, extrai-se da leitura de seu estudo que o principal é todo aquele que está em condição de influenciar de forma legítima o agente. $\mathrm{O}$ autor traz alguns exemplos de principais no setor público, decorrentes da definição estendida desse conceito: (a) cidadãos que pagam tributos e remuneram servidores públicos; (b) sindicatos de trabalhadores, cuja ação pode aumentar a despesa com salários; (c) cidadãos de determinada localidade interessados na cura de pacientes com doença infecciosa na região em que habitam, uma vez que serão beneficiados indiretamente em decorrência do controle do contágio.

Distinguem-se neste artigo os conceitos de governança, utilizado em sua acepção mais ampla, válida tanto para organizações do setor público quanto do setor privado, do conceito de governança judicial. As definições mais comuns para governança, tanto as relacionadas à governança corporativa, quanto à governança do Estado, trazem pressupostos similares. Se- 
gundo Akutsu e Guimarães (2012:185), governança “está relacionada (...) aos mecanismos de controle nas organizações, utilizados para consecução de seus objetivos". Ibanhes e colaboradores (2007:577) sugerem o seguinte conceito de governança: "ferramenta analítica para compreensão dos fatores que organizam a interação dos atores, a dinâmica dos processos e as regras do jogo". O Instituto Brasileiro de Governança Corporativa (IBGC) trata desse conceito com foco em comportamentos e finalidades, nos seguintes termos:

Governança Corporativa é o sistema pelo qual as organizações são dirigidas, monitoradas e incentivadas, envolvendo os relacionamentos entre proprietários, conselho de administração, diretoria e órgãos de controle. As boas práticas de governança corporativa convertem princípios em recomendações objetivas, alinhando interesses com a finalidade de preservar e otimizar o valor da organização, facilitando seu acesso ao capital e contribuindo para a sua longevidade. (IBGC, 2013)

Entende-se, assim, que o conceito de governança é multifacetado e plural, envolve distintas dimensões e está alinhado com práticas de gestão e de controle de organizações, tanto públicas quanto privadas. Buscando delimitar esse conceito especificamente para o Judiciário, para os efeitos deste artigo, adota-se o seguinte conceito de governança judicial: conjunto de políticas, processos, costumes, atitudes, ações, comportamentos e decisões necessários ao exercício da Justiça. Esse conceito parte do pressuposto de que governança judicial se fundamenta em instituições, isto é, em regras, em normas, em padrões de conduta socialmente construídos e legitimados, e manifesta-se em práticas, ações e comportamentos dos distintos atores do Poder Judiciário.

Os múltiplos principais referidos por Dixit (2002) são os inúmeros atores que atuam direta ou indiretamente junto ao Poder Judiciário, entre os quais podem ser destacados: partes litigantes, magistrados, servidores de tribunais, advogados, defensores públicos, membros do Ministério Público e membros do Poder Legislativo.

Para exata delimitação do objeto de pesquisa, cabe destacar que as expressões "sistema judicial" e "sistema de Justiça" não se confundem com as expressões "Poder Judiciário" ou, simplesmente, "Judiciário", e são utilizadas, neste artigo, em seu sentido amplo, englobando tanto os órgãos do Poder Judiciário relacionados no art. 92 da Constituição, quanto as funções essenciais à Justiça, arroladas nos arts. 127 a 134 da Constituição (Brasil, 2013a) — o Ministério Público, a Advocacia Pública, a Advocacia e a Defensoria Pública — e, ainda, outros agentes que, direta ou indiretamente, influenciem ou possam vir a influenciar os litígios submetidos ao Judiciário.

Tomando-se como premissa a definição de governança judicial adotada nesta pesquisa e os pressupostos da teoria da agência e da teoria de custos de transação, elaborou-se o modelo teórico inicial deste artigo, representado na figura 1: a governança judicial propriamente dita é composta de três níveis de análise — o nível de ambiente institucional; o nível de práticas de governança propriamente dito e o nível individual. Referida figura busca adaptar, para o contexto das organizações que compõem o Judiciário, o modelo de governança, proposto por Williamson (1996), para organizações em geral. 
Figura 1

Modelo teórico de governança judicial

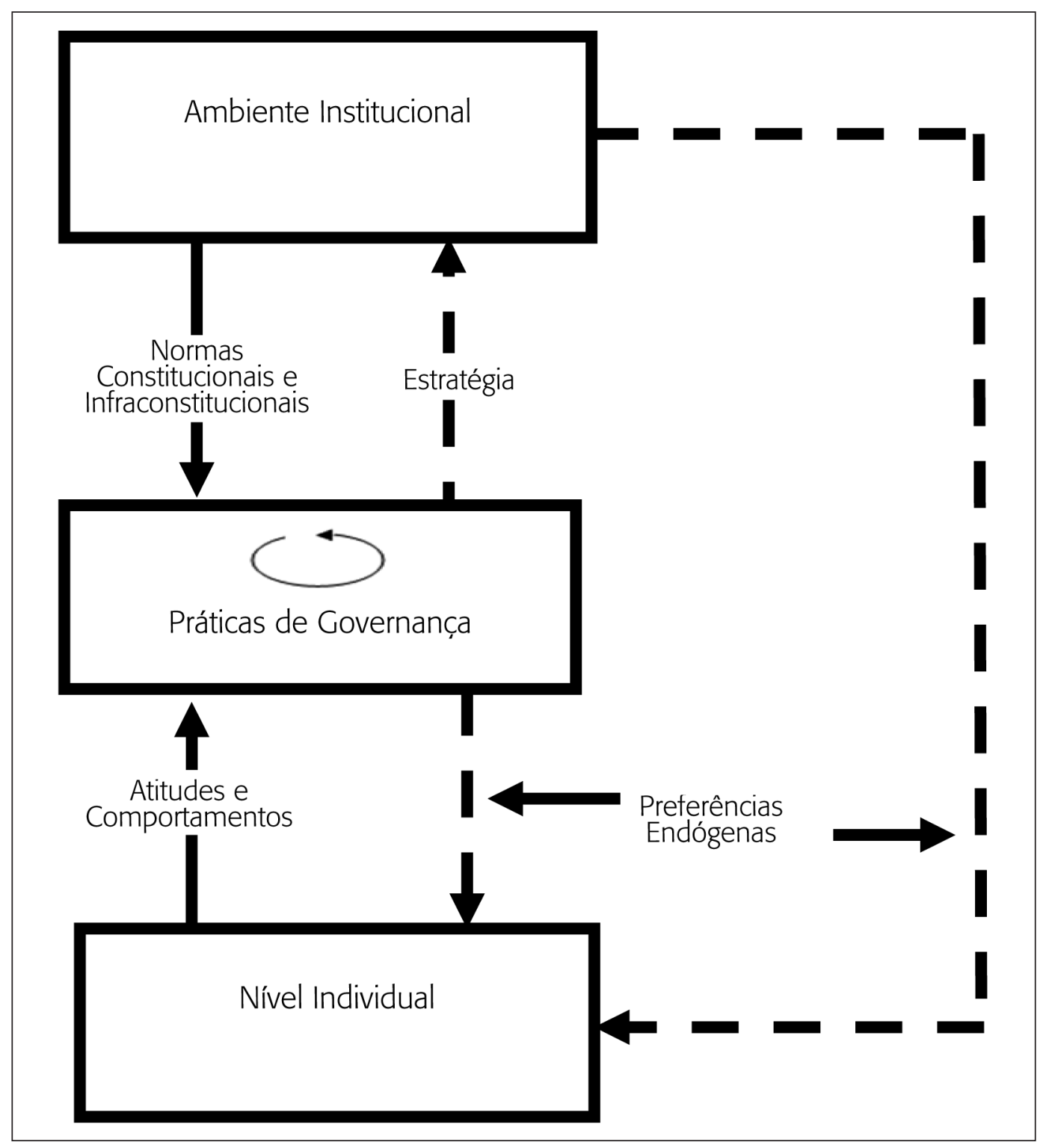

Fonte: Williamson (1996), com adaptações.

O ambiente institucional indicado na figura 1 é responsável pela definição das chamadas "regras do jogo". No Judiciário brasileiro essas regras são fixadas pela Constituição Federal e pelas normas infraconstitucionais. Eventuais mudanças nessas regras levam, em geral, 
à necessidade de mudanças nas práticas de governança. A seta circular da figura indica que, embora sejam influenciadas pelo ambiente institucional e por indivíduos, as organizações do Judiciário são autônomas e têm regras próprias. As regras próprias dessas organizações devem estar em consonância com as regras do ambiente institucional (normas constitucionais e infraconstitucionais), conforme pressupostos das teorias da agência e de custos de transação.

O nível individual refere-se aos múltiplos agentes internos do Poder Judiciário, os juízes e servidores dos tribunais. A seta que parte do nível individual para o nível de práticas de governança representa atitudes e comportamentos de tais agentes. Tais atributos estão associados aos pressupostos da teoria da agência e da teoria de custos de transação: o reconhecimento de que agentes humanos estão sujeitos à racionalidade limitada e pelo menos alguns agentes são propensos ao oportunismo.

A seta pontilhada que parte do ambiente de práticas de governança para o ambiente institucional indica a estratégia da organização. No Judiciário brasileiro, essa estratégia pode ser expressa tanto pela ampliação de serviços oferecidos pelo Poder Judiciário, tais como aqueles decorrentes da criação de Juizados Especiais Cíveis e Criminais, como pelo Plano Estratégico do Poder Judiciário, elaborado pelo Conselho Nacional de Justiça (Brasil, 2013b). As duas setas pontilhadas que partem do nível institucional e do nível de práticas de governança para o nível individual indicam a influência desses níveis nas preferências endógenas. Tais setas indicam que os indivíduos podem ser influenciados tanto pelos tribunais a que pertencem quanto pelo ambiente social em que estão inseridos.

\section{Metodologia da pesquisa}

Esta pesquisa foi realizada em três etapas. A primeira consistiu na revisão de literatura acerca de definições e teorias relativas aos conceitos de governança, de governança judicial, aos construtos teóricos relacionados ao conceito de governança judicial e às variáveis associadas a tais construtos. O modelo teórico de governança judicial apresentado na seção anterior foi construído a partir dos resultados desta etapa, na qual foram identificados construtos teóricos e variáveis associadas a tais construtos, utilizados respectivamente como categorias e subcategorias, definidas a priori para orientar a coleta e análise de dados. Os construtos e variáveis do modelo proposto fundamentaram-se, num primeiro momento, no quadro teórico adotado e em resultados de estudos teórico-empíricos identificados na revisão de literatura. Não obstante, uma vez que referidos estudos (Akutsu e Guimarães, 2012) foram realizados tanto no Brasil (quatro estudos) quanto em países estrangeiros (19 estudos), fez-se necessário avaliar a relevância desses construtos e variáveis para o contexto brasileiro. Assim, na segunda etapa, foram coletados os dados primários e secundários da pesquisa para identificar construtos e variáveis, e identificar construtos teóricos que compõem a governança de tribunais no contexto do Poder Judiciário brasileiro.

A coleta de dados primários consistiu na realização de entrevistas semiestruturadas com atores-chave. A seleção dos entrevistados fundamentou-se nos seguintes critérios, adap- 
tados para esta pesquisa a partir de regras sugeridas pela técnica snowball sampling (Biernacki e Waldorf, 1981): (a) seleção de participantes iniciais buscando diversidade de representação entre os diversos segmentos do Poder Judiciário e outros segmentos que, por sua atuação profissional, detêm conhecimento acerca do funcionamento do sistema de Justiça (Ministério Público, advogados, defensores públicos, pesquisadores da área); (b) os participantes iniciais indicaram outros atores com perfil semelhante, e assim sucessivamente, até que a pesquisa atingiu o "ponto de saturação" - momento em que os depoimentos de novos entrevistados passaram a apresentar, na avaliação dos pesquisadores, "uma certa redundância ou repetição" (Fontanella, Ricas e Turato, 2008:17); (c) as indicações sucessivas foram avaliadas pelos autores desta pesquisa, com base em conhecimento acumulado em outros trabalhos do grupo de pesquisa sobre o Poder Judiciário no tocante aos requisitos de experiência, representatividade, competência e habilidades sobre o objeto do estudo. As entrevistas foram realizadas com utilização de roteiro contendo questões abertas, que exploravam as dimensões da figura 1 e contemplavam os construtos teóricos e variáveis identificados a priori na revisão de literatura. Para cada um dos respectivos construtos (categorias definidas a priori) o roteiro continha instruções para verificar se as respostas do entrevistado contemplam as variáveis observáveis preliminarmente identificadas (subcategorias a priori) e, adicionalmente, caso o entrevistado indicasse outro construto ou variável não relacionado nas categorias e subcategorias a priori previsto inicialmente, perguntas adicionais foram formuladas de modo a aprofundar o conhecimento acerca desses construtos e variáveis.

Buscando minimizar riscos de viés acrítico ou excessivamente subjetivista, o fechamento amostral por saturação teórica foi operacionalizado observando-se as recomendações de Fontanella, Ricas e Turato (2008:25-26). Conforme destacam os autores, "o ponto de saturação depende indiretamente do referencial teórico usado pelo pesquisador e do recorte do objeto e diretamente dos objetivos definidos para a pesquisa, do nível de profundidade a ser explorado (dependente do referencial teórico) e da homogeneidade da população estudada", devendo-se evitar "a simples menção à utilização desse recurso metodológico". Neste artigo, destacam-se as seguintes peculiaridades que fundamentaram a averiguação da saturação: (a) a natureza exploratória do estudo; (b) a homogeneidade da população estudada no tocante ao conhecimento acerca do funcionamento do Poder Judiciário; (c) a utilização de categorias e subcategorias definidas a priori para orientar a realização de entrevistas, o que torna mais objetiva a averiguação da redundância ou petição de informações de depoimentos. A avaliação da saturação foi feita de modo contínuo, com reavaliação a cada nova entrevista. Verificou-se que, a partir da sexta entrevista, acréscimos às manifestações anteriores tornaram-se raros; após mais quatro entrevistas, os pesquisadores avaliaram que seria improvável que novas ideias relevantes surgissem.

A amostra final consistiu de 10 entrevistas, realizadas no período de agosto de 2012 a março de 2013, assim distribuídas: um advogado; um defensor público; dois magistrados (sendo um juiz que atua em vara de $1^{\mathrm{a}}$ instância e um desembargador que atua em tribunal de $2^{2}$ instância); um membro do Ministério Público; dois dirigentes de tribunais; dois servidores de tribunais e um servidor do Ministério Público; esses três últimos detinham conhecimento 
sobre o tema governança judicial pela sua atuação profissional e, ainda, por terem trabalhado em pesquisas em temas relacionados à administração de tribunais. Para preservar a identidade dos entrevistados, as referências aos respectivos depoimentos neste texto encontram-se codificadas de E1 a E10.

A coleta de dados secundários consistiu em pesquisa à Constituição e legislação relacionada às competências de órgãos do Poder Judiciário e em leitura de informações e documentos disponíveis em portais do Conselho Nacional de Justiça e de tribunais.

A terceira etapa consistiu na análise dos dados obtidos. Os dados coletados nas entrevistas foram gravados, transcritos e analisados por meio de análise de conteúdo, seguindo recomendações de Bardin (2011): os construtos teóricos identificados na primeira etapa da pesquisa foram utilizados como categorias definidas a priori, as quais serviram como critério para organizar os registros obtidos; da mesma forma, as variáveis preliminarmente selecionadas na primeira etapa foram utilizadas como referência inicial para dividir os registros em subcategorias definidas a priori. Para auxílio da análise de conteúdo, foi elaborada tabela com as seguintes colunas: categoria; subcategorias associadas às respectivas categorias e observações pertinentes; transcrição de frases significativas com referência às respectivas fontes (entrevistados E1 a E10).

A análise do conteúdo das transcrições levou em consideração o quadro teórico desta pesquisa e o exame de dados secundários relativos às regras constitucionais, legislação e práticas dos tribunais, disponíveis nos respectivos portais. Ao final dessa etapa, o exame dos dados primários e secundários fundamentou: (a) as definições operacionais dos construtos do modelo teórico-metodológico de governança judicial proposto neste artigo; e (b) a seleção das variáveis consideradas mais relevantes para cada um dos construtos. Foi adotado o critério da parcimônia, ao decidir entre duas ou mais possibilidades de soluções relativas à inclusão ou exclusão de construtos e de variáveis a serem selecionados para representar o modelo teórico da pesquisa, dando preferência às soluções mais simples (Brown, 2006; Hair et al., 2009).

\section{Resultados e discussão. Modelo teórico-metodológico de governança judicial}

Em face da utilização, nesta pesquisa, dos pressupostos da teoria da agência e da teoria de custos de transação, os construtos e variáveis incluídos no modelo teórico-metodológico proposto contemplam aspectos relacionados tanto ao contrato entre agente e principal, quanto transações que ocorrem nos órgãos do Poder Judiciário. Não obstante, a utilização das referidas teorias, elaboradas em contextos diversos e dirigidas para empresas, requer a transposição das suas premissas para utilização no contexto do Judiciário.

\subsection{Construtos do modelo teórico-metodológico}

A elaboração dos itens que operacionalizam as variáveis relacionadas aos construtos de uma pesquisa está, segundo Pasquali (2010), relacionada com (a) definições operacionais de cons- 
trutos formuladas de forma adequada; (b) literatura - outros testes que medem o construto; e (c) entrevista - levantamento junto à população meta. Levando em consideração tais recomendações, esta pesquisa buscou aprofundar, por meio de entrevistas, a delimitação das dimensões de governança judicial identificadas por Akutsu e Guimarães (2012), utilizadas como categorias a priori para análise de conteúdo das entrevistas. As entrevistas, contudo, não se limitaram a investigar tais categorias predefinidas: por meio de perguntas abertas, os entrevistados foram questionados acerca dos principais fatores que influenciam a governança judicial. Os dados das entrevistas e da análise documental confirmaram as categorias a priori investigadas nas entrevistas, categorias essas utilizadas para delimitação dos construtos indicados no quadro 1. Nenhuma outra categoria emergiu das entrevistas.

$$
\text { Quadro } 1
$$

\section{Definições operacionais de construtos do modelo de governança judicial}

\begin{tabular}{|c|c|}
\hline Definição operacional & Fontes \\
\hline $\begin{array}{l}\text { Acessibilidade: possibilidade oferecida aos cidadãos de recorrerem a todos os serviços judiciais } \\
\text { oferecidos pelo Poder Judiciário, de contactarem magistrados e cortes judiciais, e de serem tratados } \\
\text { da mesma forma, sem sofrerem ameaças de qualquer espécie, independentemente de sua renda, } \\
\text { condição socioeconômica ou localização geográfica de seus domicílios. }\end{array}$ & $\begin{array}{l}\text { Beer (2006); Staats, } \\
\text { Bowler e Hiskey (2005) }\end{array}$ \\
\hline $\begin{array}{l}\text { Accountability: responsabilidade, obrigação e responsabilização de quem ocupa um cargo ou } \\
\text { função pública em dar publicidade e motivar seus atos administrativos, em prestar contas perante } \\
\text { outras pessoas ou organizações, segundo os parâmetros da lei, estando envolvida a possibilidade } \\
\text { de sanção decorrente do não cumprimento dessa diretiva. No Judiciário, a accountability se divide } \\
\text { na motivação dos atos processuais e de sentenças proferidos pelos magistrados, no exercício de } \\
\text { suas funções, e na transparência dos atos de gestão dos magistrados e servidores que exercem } \\
\text { funções administrativas nos tribunais. }\end{array}$ & $\begin{array}{l}\text { Campos (1990); Mollah } \\
\text { (2010); Oliveira (2005, } \\
\text { 2009); } \\
\text { Pinho e Sacramento } \\
\text { (2009) }\end{array}$ \\
\hline $\begin{array}{l}\text { Independência: capacidade dos magistrados de agirem em conformidade com os princípios e } \\
\text { normas da Constituição e com os fatos apurados em cada caso concreto, de forma a salvaguardar } \\
\text { os direitos dos cidadãos, protegendo-os de interesses e pressões que contrariem princípios e nor- } \\
\text { mas constitucionais, advindos de qualquer origem, inclusive de eventual abuso de autoridade de } \\
\text { representantes dos poderes Executivo e Legislativo, de interesses e pressões ilegítimos oriundos } \\
\text { daqueles que os nomearam ou da própria direção dos tribunais, ou, ainda, das partes litigantes e } \\
\text { de eventuais pressões para adoção de decisões inconstitucionais de cunho populista. }\end{array}$ & $\begin{array}{l}\text { Beer (2006); Canes-Wrone } \\
\text { e colaboradores (2010); } \\
\text { Cordis (2009); Klerman } \\
\text { e Mahoney (2005); } \\
\text { Peerenboom (2006); } \\
\text { Rosenbloom (2010); } \\
\text { Staats, Bowler e Hiskey } \\
\text { (2005) }\end{array}$ \\
\hline $\begin{array}{l}\text { Recursos e Estrutura: conjunto de: (a) servidores e magistrados organizados em carreiras; (b) } \\
\text { instalações e equipamentos para servidores e magistrados exercerem adequadamente suas fun- } \\
\text { ções; (c) sistemas de informação judicial e de (d) conhecimento acumulado pelas organizações } \\
\text { do Poder Judiciário, que têm como características serem valiosos, raros, não substituíveis e difíceis } \\
\text { de serem imitados. }\end{array}$ & $\begin{array}{l}\text { Barney (1991); Bybee e } \\
\text { Pincock (2011) }\end{array}$ \\
\hline $\begin{array}{l}\text { Práticas de governança: conjunto de decisões, contratos e transações relacionados a políticas, } \\
\text { processos, costumes, atitudes, ações, comportamentos e decisões necessários à solução de } \\
\text { conflitos sociais, individuais e coletivos pelo Poder Judiciário, ancorados por regras e princípios } \\
\text { constitucionais, por leis, normas gerais e instituições, por recursos, capacidades e por práticas e } \\
\text { métodos de gestão utilizados para o planejamento, acompanhamento e controle das atividades } \\
\text { de organizações encarregadas da prestação de serviços judiciais. }\end{array}$ & $\begin{array}{l}\text { Eisenhardt (1989); Ng } \\
\text { (201 1); Williamson (1981, } \\
\text { 1991, 1996) }\end{array}$ \\
\hline
\end{tabular}




\begin{tabular}{|c|c|}
\hline Definição operacional & Fontes \\
\hline $\begin{array}{l}\text { Desempenho: resultados alcançados por magistrados e tribunais que indicam: (a) o nível de adoção } \\
\text { de boas práticas de governança judicial relacionadas aos construtos acessibilidade, accountability, } \\
\text { independência e recursos e estrutura; e (b) a qualidade dos serviços prestados pelo Poder Judiciário } \\
\text { em termos de tempo de julgamento, custo dos processos judiciais e qualidade das sentenças. }\end{array}$ & $\begin{array}{l}\text { Beer (2006); Chemin } \\
\text { (2010); Kahan (2006); } \\
\text { Ng (2011); Mendelski } \\
\text { (2009); Staats, Bowler e } \\
\text { Hiskey (2005) }\end{array}$ \\
\hline $\begin{array}{l}\text { Ambiente institucional: conjunto de práticas, princípios e regras constitucionais, leis, regulamentos, } \\
\text { costumes, valores, políticas, processos e instituiç̃̃es que delimitam e influenciam a atuação e a } \\
\text { interação de órgãos do Poder Judiciário com outros órgãos do próprio Poder Judiciário, com órgãos } \\
\text { dos poderes Executivo e Legislativo, com partes litigantes e com outros atores da sociedade que } \\
\text { se relacionem com o Poder Judiciário. }\end{array}$ & $\begin{array}{l}\text { Ng (2011); Williamson } \\
\text { (1996) }\end{array}$ \\
\hline
\end{tabular}

Fonte: Referências indicadas e dados da pesquisa.

\subsection{Variáveis do modelo teórico-metodológico}

O procedimento para identificação de variáveis do modelo proposto valeu-se de procedimento similar ao utilizado para delimitação de seus construtos teóricos: a partir de dados coletados nas entrevistas, as variáveis preliminarmente selecionadas na primeira etapa da pesquisa foram utilizadas como referência inicial para dividir os registros em subcategorias definidas $a$ priori. Os dados coletados confirmaram parte das subcategorias investigadas nas entrevistas; outras variáveis, não apontadas anteriormente na literatura, foram incluídas no modelo proposto a partir dos depoimentos colhidos e da análise efetuada à luz do modelo teórico de governança judicial adotado nesta pesquisa.

O modelo proposto não contempla variáveis associadas diretamente ao construto práticas de governança. Isso se justifica em função da revisão de literatura e dos dados coletados nas entrevistas, que indicaram, de forma convergente, que os construtos teóricos accountability, acessibilidade, independência e recursos, e estrutura podem ser utilizados para delimitar de forma mais precisa aspectos específicos que integram o construto práticas de governança.

As variáveis do modelo proposto, selecionadas para integrar os construtos do quadro 1 - exceto o construto práticas de governança, que em princípio seria explicado por outros construtos do modelo —, são apresentadas e discutidas a seguir, com indicação expressa, quando aplicável, de autores e estudos que também indicaram as mesmas variáveis. Exceto onde for indicado expressamente o contrário, as variáveis apresentadas a seguir fundamentam-se na concordância da maioria dos entrevistados de sua pertinência em relação aos respectivos construtos. Dessa forma, é feita remissão a alguns entrevistados (E1 a E10) de forma específica somente quando a variável indicada não foi referida expressamente pela maioria dos entrevistados.

\subsubsection{Construto acessibilidade}

A maioria dos entrevistados relatou influência das seguintes variáveis do construto acessibilidade, em linha com estudos identificados na revisão de literatura: distância do tribunal aos 
domicílios dos cidadãos e quantidade de magistrados por habitante (Beer, 2006); incentivo a práticas de solução extrajudicial de conflitos - negociação, mediação, conciliação e arbitragem (Mascarenhas, 2009; Veronese, 2007); oferta de serviços judiciais com rituais simplificados (Sinhoreto, 2007). As seguintes variáveis foram incluídas no modelo proposto em decorrência, exclusivamente dos depoimentos dos entrevistados: renda do cidadão que busca o Poder Judiciário; garantia de que o autor da ação não será ameaçado pelo réu (entrevistado E1); acesso dos litigantes a bons advogados (entrevistado E4); acesso da população de baixa renda a núcleos de prática jurídica (entrevistado E10). Dos depoimentos colhidos, destaca-se depoimento do entrevistado E1, sugerindo que, muitas vezes, a limitação de acesso ao Poder Judiciário é imposta por atores externos ao referido Poder e pode sofrer, também, influências de variáveis relacionadas ao construto ambiente institucional:

A Justiça é uma ameaça ao poder vigente. A gente visitava casas, especialmente aquelas no norte do Tocantins. Às vezes o agente de segurança dizia que já viu ameaças lá. O frentista não estava satisfeito e entrou na Justiça. Diz que o cara chegava e ele escutava os agentes de segurança, o grandão não fala na frente do juiz, mas ele fala nos corredores. Ele diz assim "oh, você tá lembrando que você tem mãe, você tem mulher, você tem filho, né? Ele falava assim: você sabe que pode acontecer alguma coisa com eles né?". Assim, é uma ameaça e muitos tiravam [o processo] realmente. Então, a Justiça deixa de ser acessível nessa medida também: às vezes não é nem um parâmetro da própria Justiça, é um parâmetro da sociedade que bloqueia o acesso (...).

\subsubsection{Construto accountability}

Em relação ao construto accountability, as seguintes variáveis descritas na literatura também emergiram das entrevistas: previsibilidade de decisões dos magistrados em decorrência de histórico jurisprudencial (Eisenhardt, 1989); supervisão da conduta de magistrados pela corregedoria (Peerenboom, 2006). As variáveis a seguir foram apontadas pela maioria dos entrevistados: responsabilização de magistrados e servidores pela gestão de recursos públicos; disponibilidade de informações à população sobre os processos em andamento e sobre o funcionamento das varas judiciais; possibilidade de petição e de consulta aos atos processuais por meios eletrônicos; coerência da fundamentação dos atos judiciais com os argumentos das partes e com as provas juntadas aos autos; grau de transparência dos atos administrativos e grau de publicidade dos resultados alcançados relativos à quantidade de processos julgados. O entrevistado E10 pondera que, apesar do "estigma de ser uma caixa preta", o Poder Judiciário é um dos órgãos que mais presta conta de suas ações:

Vejo o Judiciário como um dos órgãos mais fiscalizados da sociedade porque, se o juiz não decide com celeridade, com presteza, com conhecimento, ele vai para a mídia, imediatamente. Além disso, tem a fiscalização do advogado da própria parte. Aqui na Vara Penal tem a fiscalização do Ministério Público, tem os recursos que as partes interpõem quando não estão satisfeitas com a 
decisão e às vezes a gente consegue desagradar as duas partes e os dois recorrem, então acho que a transparência e a prestação de contas ocorrem diariamente. E, além da prestação jurisdicional às partes, temos também a prestação ao tribunal porque a gente trabalha com estatística, relatórios, aliás, já está tudo informatizado, o que a gente decide em tempo real já esta tudo na internet (...).

\subsubsection{Construto independência}

A literatura revisada apontou as seguintes variáveis que influenciam a independência de magistrados, também mencionadas pelos entrevistados: possibilidade de o Poder Executivo impor restrições orçamentárias aos tribunais (Beer, 2006); salários adequados de magistrados e servidores (Beer, 2006; Cordis, 2009; Klerman e Mahoney, 2005); adoção de regras de impessoalidade para nomeação de magistrados de segundo grau e de tribunais superiores (Rosenbloom, 2010; Cordis, 2009); garantia constitucional da vitaliciedade dos mandatos dos magistrados (Cordis, 2009; Klerman e Mahoney, 2005). As entrevistas indicaram, ainda para o construto independência, as seguintes variáveis que foram incorporadas ao modelo proposto: dependência de juízes de comarcas do interior de recursos alocados pelo respectivo Poder Executivo Municipal; repercussão, na imprensa, dos julgados considerados mais importantes; eficácia da proteção aos magistrados que sofrem ameaças decorrentes de deliberações judiciais. O trecho transcrito a seguir destaca palavras do entrevistado E2 relativas à dependência dos magistrados de critérios de promoção nos tribunais e, nos pequenos municípios, de recursos fornecidos pelos respectivos prefeitos para equipar as varas judiciais:

Ele [o magistrado] não tem independência sobre a carreira, sobre a evolução da carreira, a localização onde vai ficar, tudo isso é contingencial. Ele precisa realmente obedecer o sistema de antiguidade, de merecimento, precisa obedecer o sistema de recursos do tribunal. Aí você vê juiz trabalhando sem condição, sem estrutura, e de certa forma essa falta de recurso, falta de estrutura, acaba afetando a independência do julgamento. Quem dá essa estrutura para o juiz lá do interior? É o prefeito. E o prefeito é o quê de quatro em quatro anos? Um candidato. E o juiz é o quê de quatro em quatro anos? Um juiz eleitoral. Aí você entende como o Brasil funciona.

\subsubsection{Construto recursos e estrutura}

Para o construto recursos e estrutura, as variáveis apontadas pela literatura e pelos entrevistados foram: rotatividade de magistrados nas respectivas varas judiciais (Rosales-López, 2008); confiabilidade, qualidade e robustez de sistemas de informação judicial (Motsaathebe e Mnjama, 2009; Rottman, Smith e Long, 2007); adequação de práticas de incentivo às carreiras de magistrados e servidores (Schneider, 2005). Os entrevistados apontaram, 
adicionalmente, as seguintes variáveis relacionadas a esse construto: possibilidade de intercâmbio de informações entre tribunais via sistemas de informação judicial; existência de instalações e equipamentos adequados para atendimento ao público; grau de adoção, pelos tribunais, de gestão orientada por objetivos, metas e indicadores de desempenho; conhecimento, experiência e capacitação dos magistrados para julgar processos sob sua jurisdição; adequação de estruturas funcionais nos organogramas dos tribunais à gestão dos processos judiciais (entrevistado E1); conhecimento, experiência e capacitação de servidores e magistrados em gestão (entrevistado E1); nível de adoção de padronização de informações em tribunais (entrevistado E8).

O entrevistado E5 destacou que, ao contrário das comarcas em pequenos municípios, os recursos e a estrutura disponíveis para os tribunais superiores, embora possam ser relevantes, não se constituem, nesses órgãos, uma limitação para boas práticas de governança:

Não há problema de recursos orçamentários, não há problema de recursos humanos [em tribunais superiores]. Não há problema de insumos básicos necessários a um processo de gestão. Essa não é a dificuldade que pode de alguma forma comprometer a governança. Não sei se nos demais Tribunais a realidade é a mesma, nos Tribunais de Justiça a realidade é um pouco diferente, mas no STF, no TST, no STJ, nos tribunais superiores de modo geral, recursos e estrutura não é um problema (...).

\subsubsection{Construto desempenho}

Diversos aspectos relacionados ao construto desempenho, indicados na literatura revisada, foram relatados pelos entrevistados: impessoalidade das decisões judiciais (Caplan, 2010); tempo de julgamento (Van Montfort et al., 2005); custo do processo judicial para as partes litigantes (Boniface e Legg, 2010); estoque de processos judiciais não julgados (Van Montfort et al., 2005). Os entrevistados mencionaram ainda as seguintes variáveis incorporadas a esse construto: percentual de ações repetitivas julgadas com base nas orientações decorrentes de julgamento de ações de repercussão geral; percentual de ações coletivas relevantes julgadas em relação às ações individuais (entrevistado E4); percentual de cumprimento de metas do tribunal (entrevistado E1). O entrevistado E9 faz ressalvas ao desempenho do Judiciário medido estritamente pelo critério de número de processos julgados:

O que eu particularmente tenho ressalvas é que o Judiciário hoje se transformou em números. Então eu tenho dois mil processos no gabinete do fulano de tal, se ele julgou, ele é bom, ele é célere e a celeridade no julgamento não quer dizer que o julgamento tenha sido bom, ou seja, não quer dizer que tenha sido efetuado Justiça com a celeridade do julgamento. O CNJ contribuiu com isso, com a cobrança de números (...). Então todos os juízes hoje estão sujeitos à estatística, o julgamento hoje passou a ser número (...). 


\subsubsection{Construto ambiente institucional}

Para o construto ambiente institucional, a maioria dos entrevistados apontou a seguinte variável, indicada por Van Montfort e colaboradores (2005): possibilidades oferecidas pela legislação processual para interposição de recursos de caráter protelatório. As demais variáveis desse construto, apontadas nas entrevistas, foram: complexidade do jargão jurídico, da legislação e dos procedimentos judiciais; disponibilidade de delegados que atendam a população de baixa renda, de defensores públicos, de Ministério Público atuante (entrevistado E2); percentual de litígios decorrentes de inconformismo de cidadãos com ações da própria administração pública; adoção de inovações para melhorar a estrutura e o funcionamento do Poder Judiciário; existência e acompanhamento de indicadores que permitam a comparação da eficiência entre tribunais; grau de discussão de objetivos estratégicos pela alta administração dos tribunais com setores representativos da sociedade; frequência de campanhas educativas e disponibilidade de informações aos cidadãos acerca de seus direitos perante o Poder Judiciário; frequência de campanhas de Justiça Itinerante e de Justiça Comunitária (entrevistado E10); grau de diversidade entre culturas organizacionais nos órgãos do Poder Judiciário (entrevistado E5); grau de interlocução entre órgãos do Poder Judiciário (entrevistado E5).

A fala do entrevistado E4, transcrita a seguir, ilustra dois aspectos relacionados ao ambiente institucional - a complexidade da legislação e o congestionamento do Poder Judiciário decorrente de atos do próprio poder público:

Para simplificar os códigos, [há] quantos anos estão tentando modificar? E o [código] penal é de 1940; quantos anos? O código do direito é demorado mesmo, mas podem aprovar leis que deem mais celeridade ao Judiciário. Agora, queria falar uma coisa que esqueci sobre a Justiça comum federal e a estadual também: na verdade quem congestiona esse sistema é o poder público. Por que o Estado faz a opção pela litigiosidade? Porque o administrador pensa assim: "ah, o meu prazo aqui é temporário, então quanto mais eu puder botar isso para o próximo, melhor para mim". Então, ninguém quer resolver nada, aí sim seria importante também o Legislativo aprovar leis que incentivem a conciliação (...).

\subsection{Modelo teórico-metodológico de governança judicial}

A figura 2 apresenta o modelo teórico-metodológico de governança judicial proposto. Nesse modelo estão representados somente os construtos teóricos, os quais não podem ser medidos ou observáveis diretamente, sendo também denominados na literatura como variáveis latentes (Hair et al., 2009). Referidos construtos foram incluídos no modelo proposto tomando-se como referência as premissas teóricas desta pesquisa sintetizadas na figura 1: (a) o construto ambiente institucional da figura 2 associa-se ao nível de análise com a mesma denominação da figura 1; (b) o construto desempenho da figura 2 associa-se ao nível de análise individual - juízes e servidores, da figura 1; e (c) o nível de análise práticas de 
governança da figura 1 associa-se diretamente ao construto com a mesma denominação da figura 2 e, indiretamente, a outros quatro construtos: accountability; acessibilidade; independência; e recursos e estrutura.

Nesse modelo, argumenta-se, com base nos pressupostos da teoria de custos de transação, que: (a) quanto mais favoráveis forem os valores das variáveis relacionadas aos construtos accountability, acessibilidade, independência, e recursos e estrutura, melhores serão as práticas de governança desse órgão; (b) valores mais favoráveis de variáveis relacionadas ao construto desempenho relacionam-se a valores mais favoráveis de variáveis relacionadas aos construtos práticas de governança e ambiente institucional; e (c) valores mais favoráveis de variáveis relacionadas ao construto ambiente institucional relacionam-se a valores mais favoráveis de variáveis relacionadas ao construto práticas de governança.

Modelo teórico-metodológico de governança judicial

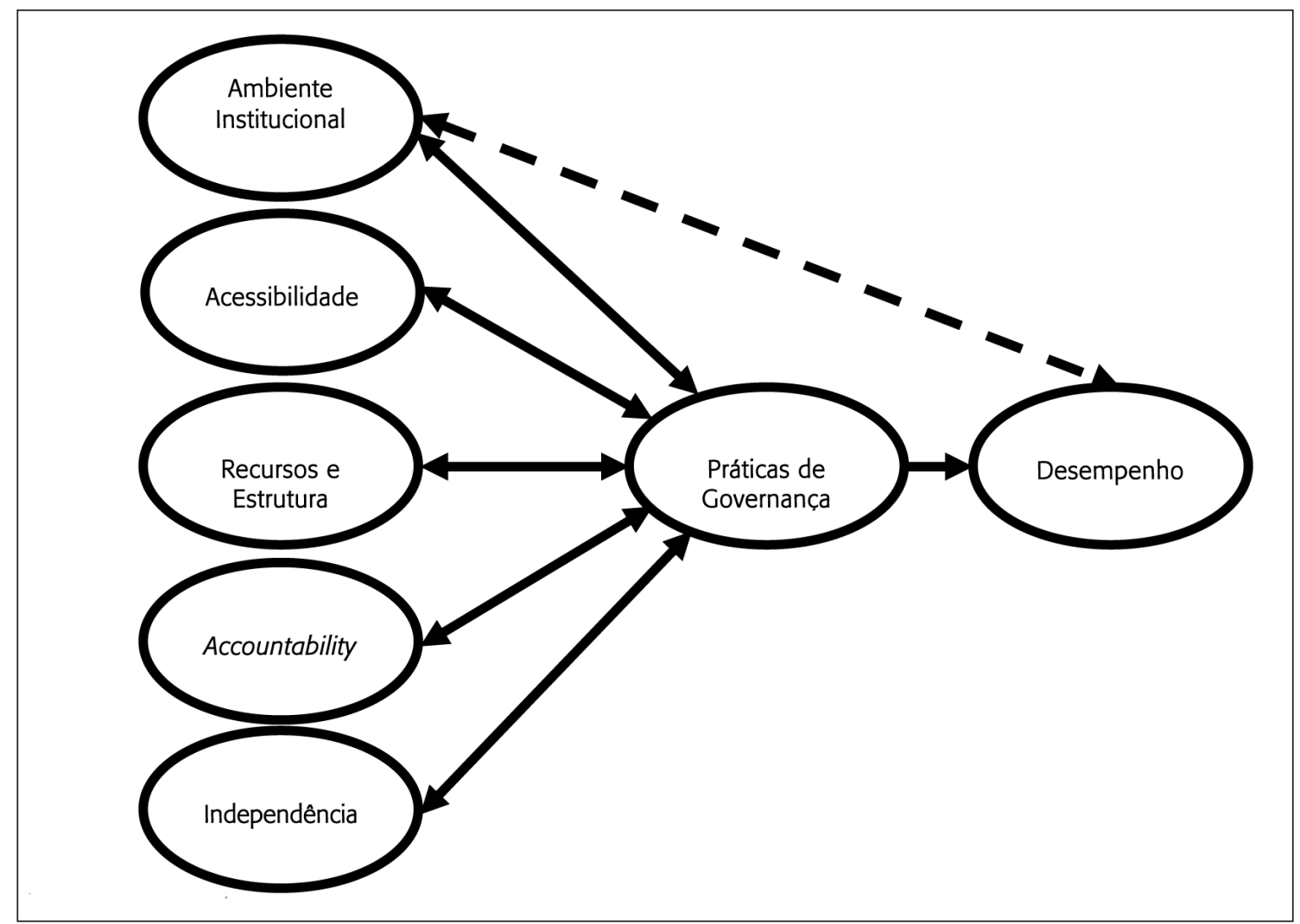

Fonte: Elaborada pelos autores.

Ao revisar a literatura sobre a teoria da agência, Eisenhardt (1989) formulou 10 proposições teóricas que podem ser testadas empiricamente, relativas às variáveis que influenciam a 
eficiência dos contratos entre agentes e principais, buscando contrapor críticos que contestam a validade empírica dessa teoria. Em consonância com o argumento dessa autora acerca da validade empírica da teoria da agência, alguns aspectos das referidas proposições estão contemplados nas variáveis do modelo teórico-metodológico, discutidas na seção 4.2.

De modo geral as proposições de Eisenhardt (1989) tratam de critérios para a escolha, pelos principais, de ênfase em contratos baseados em resultados ou em comportamento dos agentes. Segundo a autora, os contratos baseados em resultados influenciam positivamente o agente a agir de acordo com os interesses do principal e são preferíveis quando os resultados são facilmente mensuráveis; em contrapartida, os contratos baseados em comportamento são preferíveis quando a intensidade do conflito entre os objetivos do principal e do agente é baixa e em atividades que são fáceis de serem especificadas, observadas e avaliadas.

As variáveis propostas no presente estudo, discutidas na seção 4.2, incluem tanto aquelas relacionadas à medição de resultados quanto a observação dos comportamentos dos agentes. Nesse sentido, cabe destacar as mudanças introduzidas na governança do Poder Judiciário brasileiro pelo Conselho Nacional de Justiça (CNJ): os entrevistados destacaram, em especial, as inovações na gestão dos tribunais relacionadas a metas de quantidade de processos julgados e de outras metas de resultados, as quais passaram a ser incorporadas ao planejamento estratégico dos tribunais, a partir de discussões fomentadas pelo CNJ. Referidas metas podem ser consideradas, no Judiciário brasileiro, contratos baseados em resultados, complementando as regras e ritos processuais que, historicamente, delimitam o comportamento de magistrados e servidores do Poder Judiciário.

No modelo representado na figura 2, as variáveis que podem ser consideradas de uma forma mais direta como contratos baseados em resultados de acordo com a teoria da agência relacionam-se à discussão, definição, gestão e publicidade de metas de julgamento e encontram-se associadas ao construto desempenho. Em contraponto, as variáveis destinadas a revelar o comportamento dos agentes relacionam-se a sistemas de informação, à publicidade de atos de gestão e atos judiciais, à supervisão de conduta de magistrados e estão associadas, principalmente, ao construto accountability.

As variáveis do construto independência estão também relacionadas de forma indireta ao comportamento do agente, nos termos propostos por Eisenhardt (1989), mais especificamente, à independência dos magistrados ou, conforme a teoria da agência, aos aspectos que podem facilitar ou dificultar eventual conflito de objetivos entre agente e principal. De maneira similar, as variáveis que compõem os construtos acessibilidade e recursos e desempenho destinam-se a avaliar aspectos que podem facilitar ou dificultar os servidores e magistrados a alcançarem os resultados contratados (metas fixadas pelos tribunais).

As variáveis contidas no construto ambiente institucional destacam aspectos que podem influenciar a interação dos agentes (servidores do Judiciário e magistrados) com as partes litigantes, com outros órgãos públicos e com os demais atores do Poder Judiciário. O comportamento desses atores pode ser facilitado por aspectos relacionados a esse construto, a exemplo de litigantes interessados em retardar o julgamento definitivo de ações judiciais mediante interposição de recursos de caráter protelatório. 


\section{Conclusões e recomendações}

Esta pesquisa descreve um modelo teórico-metodológico, elaborado a partir de dados empíricos, para explicar a relação entre construtos teóricos e variáveis relacionadas à governança judicial. O modelo foi desenvolvido visando suprir lacunas teóricas e metodológicas sobre o referido tema. Uma das principais contribuições do modelo proposto relaciona-se à possibilidade de testar empiricamente variáveis que influenciam a eficiência de estruturas de governança e sua relação com o desempenho de tribunais. A consistência do modelo fundamenta-se na sistematização dos principais construtos teóricos e variáveis relacionados à governança judicial, delimitados a partir de análise documental, de literatura relacionada ao tema e em entrevistas.

Uma das limitações do estudo relaciona-se à seleção de entrevistados. Embora cuidados tenham sido tomados para identificação de atores-chave a serem entrevistados, buscando participantes que detivessem conhecimento sobre o tema, com diversidade de representação, até que a pesquisa atingisse o "ponto de saturação", algumas variáveis podem não ter sido apontadas pelos entrevistados. Tal risco foi mitigado, contudo, pela identificação de relação preliminar das variáveis associadas a cada um dos construtos do modelo teórico-metodológico de governança judicial antes da realização da pesquisa de campo: nenhuma das variáveis preliminarmente selecionadas deixou de ser questionada nas entrevistas realizadas. Outra limitação refere-se à seleção de categorias a priori, na medida em que isso implica uma tendência natural de coleta de dados que apoiem essas categorias. Esse risco foi minimizado pelo fato de essas categorias terem como fundamento estudos empíricos relacionados ao tema.

Como agenda de pesquisa, recomenda-se desenvolver e validar instrumento de coleta de dados tomando como referência as variáveis e construtos do modelo da figura 2. Algumas das eventuais limitações do modelo poderão ser corrigidas a partir de testes em pesquisas com amostra ampliada de respondentes, apoiadas em instrumento padronizado, cujos resultados poderão indicar, após as análises estatísticas, as variáveis mais adequadas para representar a realidade observada, isto é, aquelas que melhor permitem medir empiricamente o construto governança judicial.

\section{Referências}

AKUTSU, Luiz; GUIMARÃES, Tomas de A. Dimensões da governança judicial e sua aplicação ao sistema judicial brasileiro. Revista Direito GV, v. 8, n. 1, p. 183-202, 2012.

ANDRADE, Adriana; ROSSETTI, José P. Governança corporativa: fundamentos, desenvolvimento e tendências. 4. ed. São Paulo: Atlas S.A., 2009.

BARDIN, Laurence. Análise de conteúdo. Tradução de Luís Antero Reto e Augusto Pinheiro. São Paulo: Edições 70, 2011. 
BARNEY, Jay. Firm resources and competitive advantage. Journal of Management, v. 7, n. 1, p. 99-120, 1991.

BEER, Caroline C. Judicial performance and the rule of law in the Mexican States. Latin American Politics \& Society, v. 48, n. 3, p. 33-61, 2006.

BIERNACKI, Patrick; WALDORF, Dan. Snowball sampling: problem and techniques of chain referral sampling. Sociological Methods and Research, v. 2, n. 2, p. 141-163, 1981.

BONIFACE, Dorne; LEGG, Michael. Cost, delay and justice: the High Court of Australia recognizes the importance of case management in civil litigation - Aon Risk Services Australia Limited vs Australian National University. Common Law World Review, v. 39, p. 157-180, 2010.

BRASIL. Conselho Nacional de Justiça - CNJ. Disponível em: <www.cnj.jus.br>. Acesso em: 31 jan. 2013b.

BRASIL. Constituição da República Federativa do Brasil. Disponível em: <www.planalto.gov.br> . Acesso em: 31 jan. 2013a.

BROWN, Timothy A. Confirmatory factor analysis for applied research. Nova York: The Guilford Press, 2006.

BYBEE, Keith J.; PINCOCK, Heather. Efficient, fair, and incomprehensible: how the State "sells" its Judiciary. Law \& Policy, v. 33, n. 1, p. 1-26, jan. 2011.

CAMPOS, Ana M. Accountability: quando poderemos traduzi-la para o português? Rev. Adm. Pública, v. 24, n. 2, p. 30-50, fev./abr. 1990.

CANES-WRONE, Brandice; CLARK, Tom S.; PARK, Jee-Kwang. Judicial independence and retention elections. Journal of Law, Economics, and Organization, v. 28, n. 2, p. 211-234, 2010.

CAPLAN, Gerald. Legal autopsies: assessing the performance of judges and lawyers through the window of leading contract cases. Albany Law Review, v. 73, n. 1, p. 1-54, 2010.

CHEMIN, Matthieu. Does court speed shape economic activity? Evidence from a court reform in India. The Journal of Law, Economics, \& Organization, v. 28, n. 3, p. 1-26, nov. 2010.

CORDIS, Adriana S. Judicial checks on corruption in the United States. Economics of Governance, v. 10, n. 4, p. 375-401, 2009.

DIXIT, Avinash. Incentives and organizations in the public sector: an interpretative review. The Journal of Human Resources, v. 37, n. 4, p. 696-727, autumn 2002.

EISENHARDT, Kathleen M. Agency theory: an assessment and review. Academy of Management Review, v. 14, n. 1, p. 57-74, 1989.

FONTANELLA, Bruno José B.; RICAS, Janete; TURATO, Egberto R. Amostragem por saturação em pesquisas qualitativas em saúde: contribuições teóricas. Cad. Saúde Pública, [Saturation sampling in qualitative health research: theoretical contributions], v. 24, n. 1, p. 17-27, 2008.

HAIR, Joseph F. et al. Análise multivariada de dados. 6. ed. Porto Alegre: Boookman, 2009. 
IBANHES, Lauro C. et al. Governança e regulação na saúde: desafios para a gestão na região metropolitana de São Paulo, Brasil. Cadernos de Saúde Pública, Rio de Janeiro, v. 23, n. 3, p. 575-584, 2007.

IBGC. Instituto Brasileiro de Governança Corporativa. Governança corporativa. Disponível em: <www.ibgc.org.br/Secao.aspx?CodSecao=17>. Acesso em: 27 abr. 2013.

JENSEN, Michael C.; MECKLING, William H. Theory of the firm: managerial behavior, agency costs, and ownership structure. Journal of Financial Economics, v. 3, n. 4, p. 305-360. 1976.

KAHAN, Marcel. The demand for corporate law: statutory flexibility, judicial quality, or takeover protection? The Journal of Law, Economics, \& Organization, v. 22, n. 2, p. 340-365, 2006.

KLERMAN, Daniel M.; MAHONEY, Paul G. The value of judicial independence: evidence from eighteenth century England. American Law and Economics Review, v. 7, n. 1, p. 1-27, 2005.

MASCARENHAS, Ana C. F. Autonomia privada e autocomposição extrajudicial dos litígios. Dissertação (mestrado em direito) — Universidade Federal da Bahia, Salvador, 2009.

MENDELSKI, Martin. The impact of EU on governance reforms in post-communist Europe: a comparison between first and second-wave candidates. Romanian Journal of Political Science, v. 9, n. 2, p. 42-64, 2009.

MOLLAH, Mohamed A. H. Does the Judiciary matter for accountability of administration in Bangladesh? International Journal of Law and Management, v. 52, n. 4, p. 309-331, 2010.

MOTSAATHEBE, Lorato; MNJAMA, Nathan. The management of High Court Records in Botswana. Records Management Journal, v. 19, n. 3, p. 173-189, 2009.

NG, Gar Y. A discipline of judicial governance? Utrecht Law Review, v. 7, n. 1, p. 102-116, 2011.

OLIVEIRA, Vanessa. Judiciário e privatizações no Brasil: existe uma judicialização da política? Dados — Revista de Ciências Sociais, v. 48, n. 3, p. 559-587, 2005.

OLIVEIRA, Vanessa. Poder Judiciário: árbitro dos conflitos constitucionais entre estados e União. Lua Nova, n. 78, p. 223-250, 2009.

PASQUALI, Luiz. Testes referentes a construto: teoria e modelos de construção. In: PASQUALI, Luiz et al. Instrumentação psicológica: fundamentos e práticas. Porto Alegre: Artmed, 2010. p. 165-198.

PEERENBOOM, Randall. Judicial independence and judicial accountability: an empirical study of individual case supervision. The China Journal, n. 55, p. 67-92, jan. 2006.

PERES, Ursula D. Custos de transação e estrutura de governança no setor público. Revista Brasileira de Gestão de Negócios, v. 9, n. 24, p. 15-30, maio/ago. 2007.

PINHO, José A. G.; SACRAMENTO, Ana R. S. Accountability: já podemos traduzi-la para o português? Rev. Adm. Pública, v. 43, n. 6, p. 1343-1368, 2009.

ROSALES-LÓPEZ, Virginia. Economics of court performance: an empirical analysis. European Journal of Law and Economics, v. 25, n. 3, p. 231-251, 2008. 
ROSENBLOOM, David H. George W. Bush, the Supreme Court, and the pursuit of "big government conservatism" in federal personnel management. Review of Public Personnel Administration, v. 30, n. 4, p. 467-485, 2010.

ROTTMAN, Joseph W.; SMITH, L. Douglas.; LONG, David A. Implementing judicial management systems within an integrated Justice information framework: a case study on information systems development in the public sector. The American Review of Public Administration, v. 37, n. 4, p. 436457, dez. 2007.

SADEK, Maria T. A. Poder Judiciário: perspectivas de reforma. Opinião Pública, v. 10, n. 1, p. 1-62, 2004.

SCHNEIDER, Martin R. Judicial career incentives and court performance: an empirical study of the German Labour Courts of Appeal. European Journal of Law and Economics, v. 20, n. 2, p. 127-144, 2005.

SINHORETO, Jacqueline. Reforma da Justiça (estudo de caso). Tempo Social — Revista de Sociologia da USP, v. 19, n. 2, p. 157-177, 2007.

STAATS, Joseph L.; BOWLER, Shaun; HISKEY, Jonathan T. Measuring judicial performance in Latin America. Latin American Politics \& Society, v. 47, n. 4, p. 77-106, 2005.

VAN MONTFORT, André. J. G. M. et al. The sooner the better: management of time in district courts. International Journal of the Sociology, v. 33, n. 1, p. 35-51, 2005.

VERONESE, Alexandre. Projetos judiciários de acesso à justiça: entre assistência social e serviços legais. Revista Direito GV, v. 3, n. 1, p. 13-34, 2007.

WILLIAMSON, Oliver. Comparative economic organization: the analysis of discrete structural alternatives. Administrative Science Quartely, v. 36, n. 2, p. 269-296, 1991.

WILLIAMSON, Oliver. Mechanisms of governance. Nova York: Oxford University Press, 1996.

WILLIAMSON, Oliver E. The economics of organization: the transaction cost approach. The American Journal of Sociology, v. 87, n. 3, p. 548-577, 1981.

Luiz Akutsu é doutor em administração pela Universidade de Brasília (UnB) e auditor federal de controle externo do Tribunal de Contas da União (TCU). E-mail: luiz.akutsu@gmail.com.

Tomás de Aquino Guimarães é professor titular do Programa de Pós-Graduação em Administração da Universidade de Brasília (PPGA/UnB). E-mail: tomas.aquino.guimaraes@gmail.com. 